\title{
Critical Facilities for Active Participation in Learning Networks
}

Citation for published version (APA):

Hummel, H., Tattersall, C., Burgos, D., Brouns, F., Kurvers, H., \& Koper, R. (2006). Critical Facilities for Active Participation in Learning Networks. International Journal of Web-based Communities, 2(1), 81-99.

https://doi.org/10.1504/IJWBC.2006.008617

\section{DOI:}

10.1504/IJWBC.2006.008617

Document status and date:

Published: $12 / 01 / 2006$

Document Version:

Peer reviewed version

Please check the document version of this publication:

- A submitted manuscript is the version of the article upon submission and before peer-review. There can be important differences between the submitted version and the official published version of record. People interested in the research are advised to contact the author for the final version of the publication, or visit the DOI to the publisher's website.

- The final author version and the galley proof are versions of the publication after peer review.

- The final published version features the final layout of the paper including the volume, issue and page numbers.

Link to publication

\section{General rights}

Copyright and moral rights for the publications made accessible in the public portal are retained by the authors and/or other copyright owners and it is a condition of accessing publications that users recognise and abide by the legal requirements associated with these rights.

- Users may download and print one copy of any publication from the public portal for the purpose of private study or research.

- You may not further distribute the material or use it for any profit-making activity or commercial gain

- You may freely distribute the URL identifying the publication in the public portal.

If the publication is distributed under the terms of Article 25fa of the Dutch Copyright Act, indicated by the "Taverne" license above, please follow below link for the End User Agreement:

https://www.ou.nl/taverne-agreement

Take down policy

If you believe that this document breaches copyright please contact us at:

pure-support@ou.nl

providing details and we will investigate your claim.

Downloaded from https://research.ou.nl/ on date: 26 Apr. 2023 


\title{
Critical Facilities for Active Participation in Learning Networks
}

\author{
Hans G. K. Hummel, Colin Tattersall, Daniel Burgos, \\ Francis Brouns, Hub Kurvers \& Rob Koper \\ Educational Technology Expertise Centre \\ Open University of the Netherlands
}

\begin{abstract}
Author notes
The authors would like to thank the management and staff of the Schloss Dagstuhl International Conference and Research Center for Computer Science for providing a pleasant, stimulating and well-organized environment for the writing of this article. Furthers thanks go to the community members from all over the world for participating in the learning networks. Correspondence concerning this article should be addressed to Hans G. K. Hummel, Educational Technology Expertise Centre, Open University of the Netherlands, Valkenburgerweg 177, 6419 AT Heerlen, The Netherlands, E-mail: hans.hummel@ou.nl, Fax: +31 455762907.
\end{abstract}

Abstract
This article investigates conditions for increasing active participation in on-line communities. As a case study, we use three generations of facilities designed to promote learning in the area of Educational Modelling Languages. Following a description of early experience with a conventional web site and with a community site offering facilities for collaboration, we describe a pilot implementation of a Learning Network. Preliminary participation data (both passive and active) is reported, together with lessons learned while setting up the pilot. Early experiences reveal that clear policies, usability and reward systems are of importance when facilitating a Learning Network. We reveal first (positive) findings with introducing such a reward mechanism in the network. Our 'lessons learned' are phrased in terms of recommendations which will be used to guide subsequent Learning Network implementations.

\section{Keywords}

learning network, participation, seeding, learning design, exchange

\section{Biographical notes}

All authors work at the Educational Technology Expertise Centre of the Open University of the Netherlands (OUNL), currently investigating critical facilities for lifelong learning networks (Technology Development Programme 2003-2008).

Dr. H.G.K. Hummel (1960) holds a PhD in educational technology and degrees in pedagogy and educational psychology. He has coordinated innovative projects applying ICT in primary and vocational education for both a research institute and a publishing company. Hans has worked at OUNL since 1987, co-developing dozens of distance courses, and leading the development of interactive computer programs in a variety of domains. He was OUNL-spokesman for corporate communications related to innovation and involved in the development of IMS Learning Design, in learning technologies standardisation workgroups (IMS/LD, Prometeus/Pedagogies).

Drs. D. Burgos (1970) holds degrees in Computer Science, Education and Business Administration. Daniel recently joined the OUNL as a Researcher in Educational Technology, after having worked for fourteen years as a teacher, multimedia developer and academic manager in Europe and South America on these topics, also with his own company. He is currently working with IMS Learning Design, adaptive learning and e-learning systems within various (European) projects.

Dr. C. Tattersall (1965) gained a degree in computational science (1986, University of Leeds, United Kingdom) before conducting research into text generation for intelligent help systems at Leeds University's Computer Based Learning Unit, resulting in his $\mathrm{PhD}$ (1990). Colin worked in both the telecommunications and software industries before joining OUNL in late 2002, where his work focuses on innovation and standardisation in e-learning.

Dr. Ir. F.M.R. Brouns (1964) obtained a PhD in Agriculture and a degree in biology. Francis has been working at the OUNL since 1998 as programmer / system architect. She was involved in the development of EML and the IMS Learning Design specifications as well as authoring and runtime environments for these specifications.

Ir. H.J. Kurvers (1961) holds a degree in electrical engineering. Working at the OUNL as a programmer / system architect since 1991, Hub has been involved in the technical design an implementation of interactive multimedia computer practicals in a variety of domains. 
Prof. Dr. E.J.R. Koper (1957) holds a degree in educational psychology (1986, University of Tilburg) and a PhD in educational technology. He worked as a teacher in higher education and was director of a teacher training company, joining OUNL in 1987. Rob became head of ICT application development and now holds a chair in Educational Technology (1998). He was the programme manager for R\&D into Learning Technologies (1998-2002), that resulted in EML, IMS Learning Design, and tools for authoring and publishing, and currently leads the new program on Learning Networks (2003-2008).

\section{INTRODUCTION}

Both higher and distance education are currently exploring new technological possibilities for lifelong learning. Consortia of universities are being formed to share learning resources and exchange information in communities of practice. Today's lifelong learner needs to update knowledge continuously and acquire skills and competences given personal, societal or employment related motives (Aspin \& Chapman, 2000; Field, 2001; Griffin, 1999). Lifelong learning facilities need to be designed to meet the needs of learners at various levels of competence throughout their lives. However, the introduction of these facilities will not be sufficient for their success if potential learners are not motivated to use them. People should be able, and encouraged, to use and contribute to the facilities (Fischer \& Ostwald, 2002). This article addresses the conditions for learner-controlled (as opposed to programme-centred) participation in learning facilities, both passively and actively, and focuses on policies, usability and the structuring of information in advance as approaches to stimulating active participation.

\subsection{Information ecology perspective}

We view learner participation from the information ecology perspective (e.g., Card, Robertson, \& York, 1996). As Guzdial notes (1997), participation and exchange can be studied at a high level of aggregation to understand information spaces in terms of searching, making (contributing, e.g. postings, replies, ratings, uploads) and using (consuming, e.g. page reads, downloads) information. In learning ecologies (Looi, 2001), activity can be monitored without knowing whether learning is taking place. The benefits of this approach are: 1 . that although it is hard to determine whether individuals are learning, we can determine whether mediating conditions are being met; 2. that designers can learn from these mediating behaviours when information spaces and facilities are still 'under construction', without having to perform in depth analysis of the information; and 3. that the total population of learners can be monitored, instead of smaller and selected groups in controlled experimentation. Our aggregated analyses focuses on reading, writing and rating in forums as indicators of participation.

\section{INITIAL EXPERIENCES}

The study reported here concerns facilities designed to promote learning in the area of Educational Modelling Languages (Rawlings, Van Rosmalen, Koper, Rodrigues-Artacho, \& Lefrere, 2002). The initial period of study (2001-2002) revolved around the Educational Modelling Language EML (Koper, Hermans, Vogten, \& Brouns, 2000), while the latter period (2003-2004) focused on its successor, the IMS Learning Design Specification (IMS-LD, 2003).

\subsection{First experiences: the EML web site}

EML was released as a specification in December 2000 following a period of use at the Open University of the Netherlands. In order to promote its use in a wider context, a web site (reachable via eml.ou.nl) was created through which the specification could be downloaded and from which newsletters were sent to subscribed participants. The growth in registered users (passive participation) at the EML web site is shown in Figure 1.

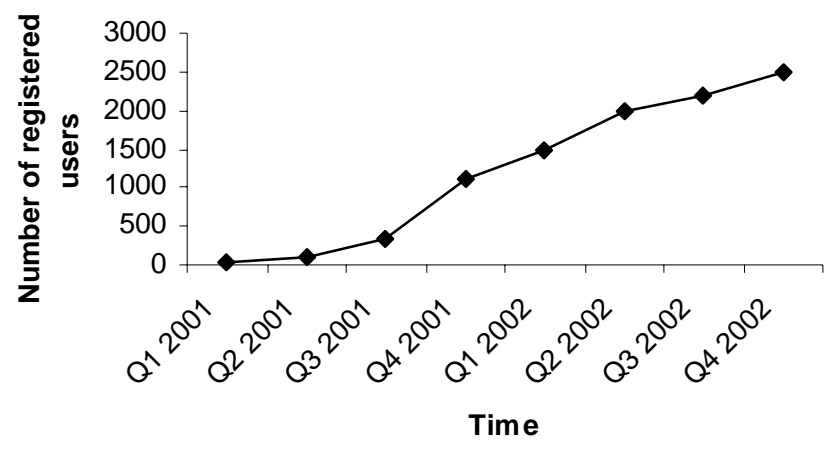

Figure 1 Growth in registered users at the EML site 
Although large numbers of the EML specification were downloaded, no channel was available to potential adopters of the specification to seek guidance, share experiences, offer examples, and help distribute the load of learning about Educational Modelling Languages beyond the originators of the specification (the Open University of the Netherlands).

\subsection{Opening up a dialogue: from web site to forums}

In order to open up possibilities for dialogue concerning Educational Modelling Languages, the EML web site was migrated onto a platform offering forums in which registered users could post and reply to messages (VBulletin, 2004). Figure 2 shows the user interface.

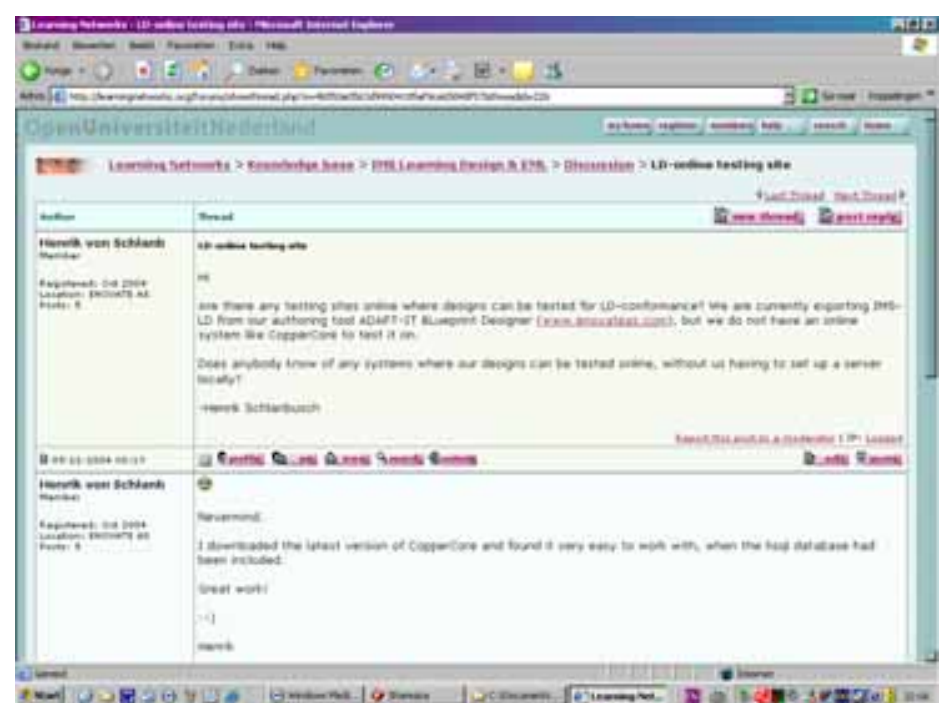

Figure 2 The forum-based facility at www.learningnetworks.org

Users registered on the EML web site were migrated over to the new facility, known as www.learningnetworks.org. The new facility was promoted during 2003 and 2004, although, as figure 3 shows, the number of registered users remained stable during this period.

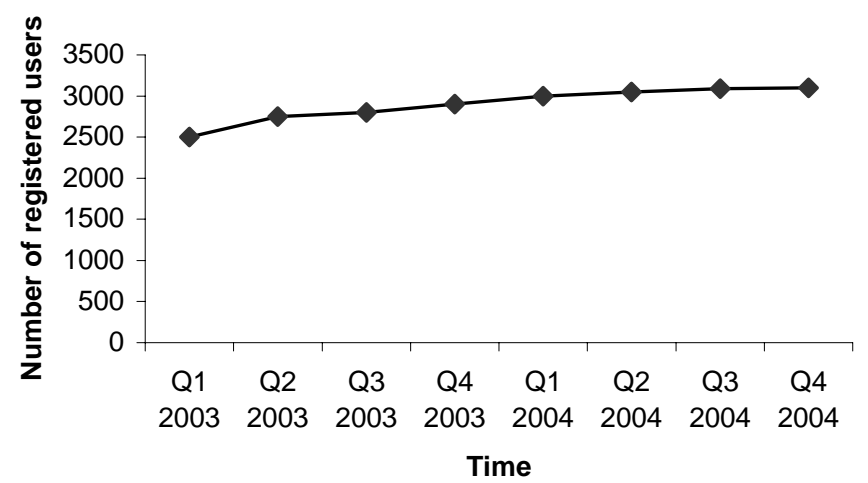

Figure 3 Growth in registered users at www.learningnetworks.org

Page views during this period numbered thousands per day, and registered users now had the opportunity to participate more actively by posting messages and replying to the postings of others. Table 1 shows the total number of contributions made during the period of study and indicates how many of these contributions were made by the originators of the facility.

Table 1 Contributions made at www.learningnetworks.org

\begin{tabular}{|l|l|l|}
\hline Forum & Posts & Posts made by originators \\
\hline News & 59 & 58 \\
\hline IMS Learning Design \& EML & 74 & 57 \\
\hline
\end{tabular}




\begin{tabular}{|l|l|l|}
\hline Standardization & 9 & 7 \\
\hline Valkenburg Group & 8 & 5 \\
\hline Alfanet & 3 & 3 \\
\hline
\end{tabular}

An impression of the levels of active and passive participation at www.learningnetworks.org can be gained from Table 2, which shows, for an example forum, the number of postings and the number of posting views.

Table 2 Active (replies) and passive (views) participation in a forum

\begin{tabular}{|l|l|l|}
\hline Thread & Replies & Views \\
\hline LD-online testing site & 2 & 245 \\
\hline Environments definition & 2 & 412 \\
\hline Referencing external Units of Learning & 4 & 952 \\
\hline LD and IMS MD: taxonomies and vocabularies & 1 & 469 \\
\hline Upcoming workshops & 0 & 305 \\
\hline Help & 2 & 558 \\
\hline New 6th Framework Coordination Action: UNFOLD & 0 & 438 \\
\hline IMS-LD Editor Announcement & 0 & 549 \\
\hline
\end{tabular}

Clearly, although the communication channel was available, participants were not moving over to take an active role in the learning process as we had hoped.

\section{LN4LD: A PILOT LEARNING NETWORK}

Our experiences with 'free-riding' (Olsen, 1965), or 'lurking', i.e. when people do not contribute, or cease to contribute, to a community, led us to reconsider our approach and to draw on the area of self-organising systems.

\subsection{Online self-organising social systems and the issue of structuring}

Wiley and Edwards (2002) investigate the potential of Online Self-Organizing Social Systems (OSOSS) in which students provide each other with peer feedback without any guiding authority, such as learning through Collaborative Problem Solving (CPS). According to Nelson (1999) the attributes of the ideal CPS learning environment are simply: “... conducive to collaboration, experimentation, and inquiry, an environment which encourages an open exchange of ideas and information”. Wiley and Edwards focus their research on web-based CSCL infrastructures, that are considered as a 'fertile primordial soup' from which OSOSS can just 'simply' emerge without a central authority adding content, commentary, structure or user support in advance.

However, researchers have also stated that for effective problem-solving and peer feedback to occur there also “... seems to be a need to structure the learning in small group interaction in advance in a way that will prompt students to elaborate the problem, reflect on the solution process, and really construct relationships between prior and new knowledge" (Mevarech \& Kramarski, 2003). By which means and to which extent collaboration should be structured in advance, whether this should be face-to-face or computer-supported, how individual and group support could be balanced, and what 'collaborative tools' could be applied in collaboration remain largely unresolved issues. But it has become apparent that characteristics of the task environment influence collaborative knowledge construction activities (Henri, 1992, 1994) and some researchers have mentioned 'structure' as the key variable to invoke a more focused and more effective exchange of information. We took an intermediate stance by adding some content and structure to 'seed' the information space for others to add and elaborate, based on the concept of 'courses as seeds' (De Paula, Fisher \& Ostwald, 2001; De Paula, 2003).

With the ideas of self-organisation and seeding in mind, our third attempt to promote learning in the area of Educational Modelling Languages was to implement a Learning Network. Learning Networks use information and computer technology to network together learners, institutions and learning objects in such a way that the network can self-organise (Koper, Pannekeet, Hendriks, \& Hummel, 2004). Learning Networks (LNs) are twomode networks (Wasserman \& Faust, 1994) represented as a graph with nodes, where the nodes are ' $L N$ members' and 'Activity Nodes' (ANs). As described by Koper and Tattersall (2004), ANs can be anything that is available to support learning, such as a course, a workshop, a conference, a lesson, an internet learning resource, 
et cetera. Central to the notion of a Learning Network is the idea that all participants are in a position to contribute, within the constraints of any policies that may be operating.

\subsection{Requirements and architecture}

As Preece (2000) notes, not only the usability aspects of a facility such as an LN are of importance but also sociability. Sociability requires careful communication of the purpose and policies (values) of the community (e.g., joining or leaving requirements; bylaws; codes of practice for communication; rules for moderation; issues of privacy and trust; practices for distinguishing professionally contributed information; rules for copyright; and democracy and free speech in the community). Different aspects and steps in setting up policy management, together with other requirements and use cases for building a community of practice, have been described by Koper et al (2004) in more detail. Table 3 lists requirements for Learning Networks, highlighting those of special interest for participation and exchange.

Table 3 General requirements for Learning Networks (those of special interest for exchange and participation are highlighted). Taken from: Koper, Pannekeet, Hendriks, \& Hummel ( 2004)

\begin{tabular}{|c|c|}
\hline No & General Requirement \\
\hline 1 & $\begin{array}{l}\text { The objective of any LN is to offer long lasting, evolving facilities for the members to improve } \\
\text { and share their expertise and build the competencies needed in a disciplinary field. }\end{array}$ \\
\hline 2 & $\begin{array}{l}\text { The LN should offer facilities for members to create, search, get/access and study LNs, ANs, } \\
\text { UOLs and learning resources as a means of building expertise and competence. }\end{array}$ \\
\hline 3 & $\begin{array}{l}\text { The LN should be governed by community policies that reflect the common goals and values of } \\
\text { the membership. Instruments must be available to manage, change and apply the different policies } \\
\text { (LN objectives and values, terms of use, standards and quality, reward system, membership } \\
\text { policies). }\end{array}$ \\
\hline 4 & $\begin{array}{l}\text { The LN should have facilities to assign its members to specialized roles according to certain role } \\
\text { policies. Roles are not fixed. Role change policies must be available. }\end{array}$ \\
\hline 5 & $\begin{array}{l}\text { The LN should offer facilities to search for ANs and UOLs that match the members needs and } \\
\text { LNs, and should support flexible learning routes (positioning, logging of tracks of others and } \\
\text { usage patterns). }\end{array}$ \\
\hline 6 & $\begin{array}{l}\text { The LN should contain ANs and UOLs for different levels of expertise to serve a heterogeneous } \\
\text { membership. }\end{array}$ \\
\hline 7 & $\begin{array}{l}\text { The LN should offer ANs and UOLs in which learning designs are based on pedagogical models } \\
\text { that are selected as suitable for the discipline, the membership and the learning objectives (e.g. } \\
\text { problem-based and learner-centred, formative assessment, knowledge and community-centred). }\end{array}$ \\
\hline 8 & $\begin{array}{l}\text { The LN should facilitate a high level of dialogue, interaction and collaboration within the LN and } \\
\text { within ANs. }\end{array}$ \\
\hline 9 & The LN should support guidance/scaffolding, or more generally: support activities. \\
\hline 10 & $\begin{array}{l}\text { The LN should support distributed control. The LN managers are LN members with specific } \\
\text { assigned management tasks (according to the change policies). }\end{array}$ \\
\hline 11 & $\begin{array}{l}\text { The LN shoud provide first order and second order feedback to all members to support the } \\
\text { optimization of organization and quality according to self-organization principles. }\end{array}$ \\
\hline 12 & $\begin{array}{l}\text { An explicit exchange reward system which is consistent with self-organization principles should } \\
\text { be available in the LN. }\end{array}$ \\
\hline 13 & The LN should have distributed, ubiquitous access. \\
\hline 14 & $\begin{array}{l}\text { The LN should have facilities to provide automated support (software agents) for some members' } \\
\text { tasks to make performance more efficient. }\end{array}$ \\
\hline 15 & $\begin{array}{l}\text { The LN should use community standards for interoperability (e.g. units of learning, learner } \\
\text { dossiers, learning/knowledge services and resources) and provides facilities to discuss and change } \\
\text { these. }\end{array}$ \\
\hline 16 & $\begin{array}{l}\text { The LN should find the right balance between usability for the participants and } \\
\text { flexibility/complexity (information/training facilities, adaptable user-interfaces, error free } \\
\text { technology). }\end{array}$ \\
\hline
\end{tabular}

When the environment is reluctant to start using the LN, it is necessary to give special attention to activities like: 1 recruiting new members, mainly by communicating the purpose and policies; 2. promoting use within existing users, e.g. by providing facilities to advertise personal productions; 3. providing training facilities for new and existing members to overcome barriers at the personal level.

Our pilot implementation is known as the Learning Network for Learning Design (LN4LD) and was carried out in the authentic context of the EC-funded UNFOLD project (IST-2002-1-507835) which aims to provide information for those interested in getting to know and implement the IMS-LD specification.

In addition to serving as a mechanism to facilitate learning about IMS-LD, LN4LD was created with two aims: 1. ensure that the Learning Networks architectural model could be implemented; and 2. to examine 
whether the resulting LN meets the functionalities for participation and exchange of information (Koper et al., 2004; Müller, Spiliopoulou, \& Lenz, 2001).

PHP-Nuke (2004) was used to implement the LN-layer of the architecture, which provides information about the different ANs available in the LN (see Figure 4).

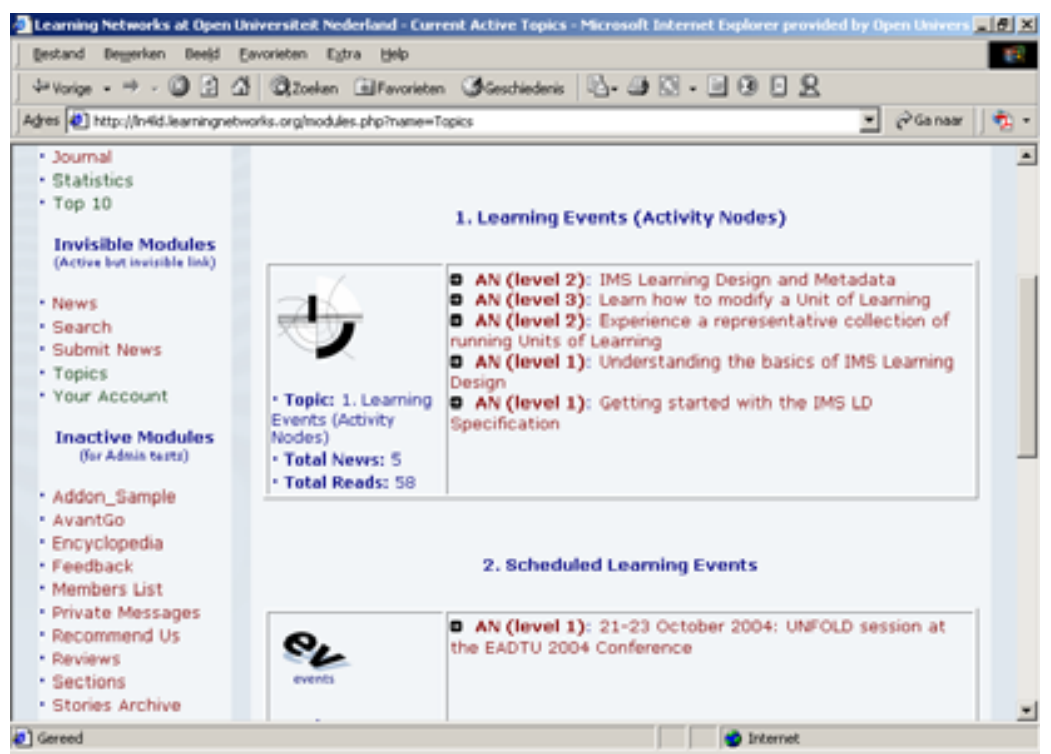

Figure 4 The Learning Network layer of LN4LD

The actual content and processes in ANs can be delivered in a variety of Learning Management Systems and Moodle (Dougiamas, 2004) was used in this delivery role in LN4LD.

Before launching the LN we 'seeded' it with four course ANs (De Paula, Fischer, \& Ostwald, 2001; De Paula, 2003). The seeds were: 'Understanding the basics of Learning Design', 'Getting started with Learning Design', 'How to modify a Unit of Learning' and 'Experiencing a representative collection of running Units of Learning'. The basic idea of a LN now was that, by making suggestions for new ANs in a special forum, all members could acquire rights to add and fill their own ANs (in Moodle) and further shape the LN. Such an 'additional' AN is 'IMS Learning Design and Meta Data', created after some general discussion in the PHPNuke 'Suggestions for new ANs' forum. Specific forums related to LD-content were offered in Moodle 'courses': one general forum for each AN, and more specific forums for each assignment within an AN. It was possible to rate ANs (in PHP-Nuke) and postings in all forums (in Moodle) (see figure 5). In LN4LD the collection of 'seeded courses' was an initial set of activity nodes, with each node being described and filled minimally with learning objectives, forums, initial postings, source material, self assessment question, et cetera.

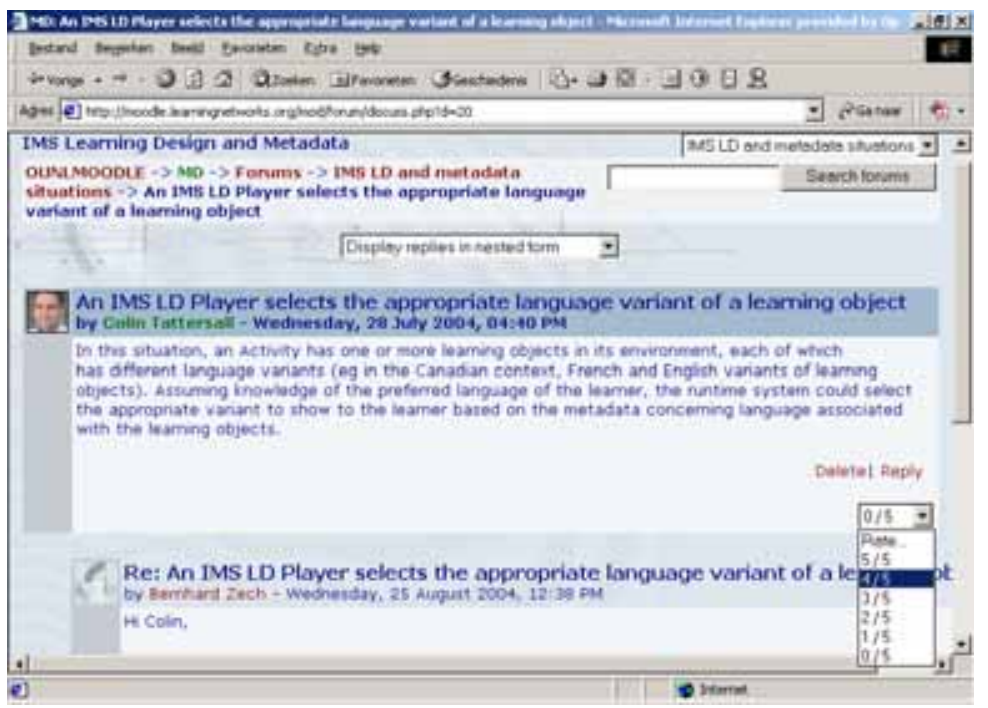

Figure 5 Rating a posting in a Moodle forum 


\section{PRELIMINARY DATA AND FIRST EXPERIENCES WITH LN4LD}

In line with the information ecology perspective, we logged the number of participants and both passive and active participation data during the first three months after launching the LN4LD. After describing these preliminary data we present some 'lessons learned', while setting up the network, in order to shed some light onto the data.

\subsection{Number of participants}

Unregistered visitors could access the LN4LD homepage and read some news and resources, but not the general forums. They could read the list of ANs but could not access them. Once registered and in possession of a PHP-Nuke account, users could access and participate in the forums, and were considered as participants. During three months (14 weeks) after launch we monitored the number of participants weekly. Figure 6 shows the increase in numbers.

Over this period, a weekly average of about 73 participants $(M=73.4, S D=23.8)$ were in the study, from both universities and corporate industries across the world interested in learning technology. Figure 6 examines whether interventions introduced during this period influenced increase, but visual inspection of the graph shows this not to be the case. After placing a recruitment text on www.learningnetworks.org (with about 3,000 registered) we expected about 200 persons to register for LN4LD. Since the actual amount remained disappointing, we tried to attract more people by: introducing a forum for personal introductions; announcing the network on a national e-learning site for universities, announcing the network during a face-to-face UNFOLD meeting and e-learning conference and by adapting the text of the home page.

Analysis of the log data reveals that, of the total of 104 participants, 58 registered but did not visit the network again (non-starters). Log data in Moodle reveals that about 20 participants regularly visited the ANs and forums in Moodle.

\subsection{Reading (passive participation)}

When we look at the total number of page hits in Nuke (including news and various resources) during the period of three months, we count 12,011 page reads, equally divided over time (although temporarily lower due to summer break in August). People downloaded 427 items (manuals, articles, and other resources). When we focus on the AN descriptions ('stories' in Nuke), we count 64 reads, equally divided over time. Participants (excluding moderators) in specific ANs were distributed as follows: 'Understanding ...' (10 participants); 'Getting started ...' (8 participants); 'How to modify ...' (6 participants); 'Experiencing ...' (4 participants); and 'Metadata' (6 participants). Study activity and level of passive participation can therefore be considered as quite substantial.

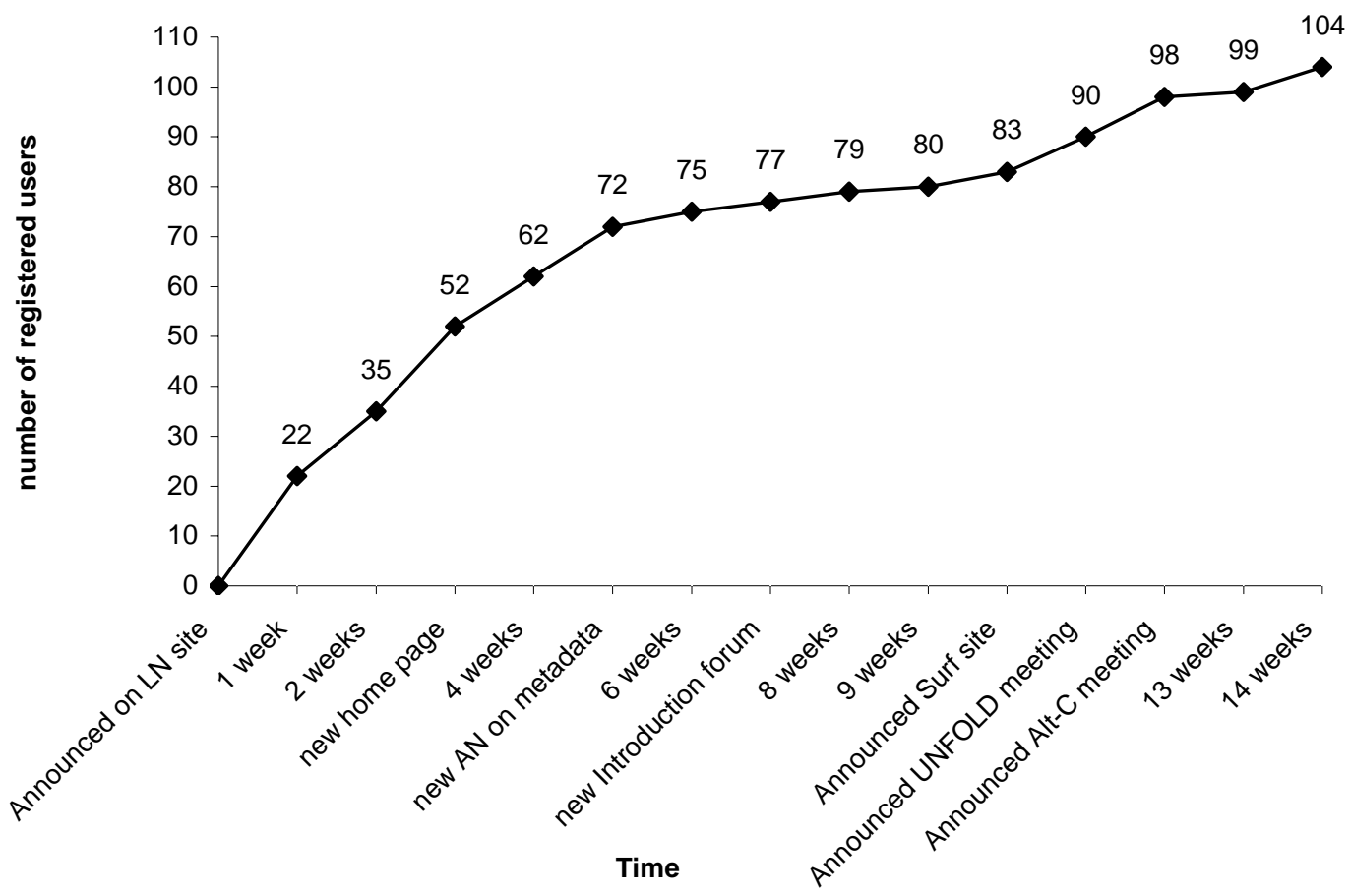

Figure 6 Numbers of participants and interventions with respect to LN4LD 


\subsection{Writing (active participation)}

When it comes to active participation, results have remained rather thin on the ground so far. At the end of the period, PHP-Nuke contained only 24 articles posted in the three general forums: 'Suggestions for new ANs' (13); 'Suggestions for improving LN4LD' (5); and the 'Introduction' forum (6). No ANs were rated in Nuke. No posting or replies were rated (neither in Nuke or Moodle) at all. When we focus on the actual ANs (modelled as 'courses' in Moodle), we count only 24 articles posted in a total of 13 forums, divided over 5 ANs. Exchange of information on level of active participation still have to be considered as quite disappointing. However, at the same time we can consider it as a very substantial improvement when compared to the (number of active posts number of registered users) ratio observed in the VBulletin predecessor of LN4LD. As Table 1 shows, this ratio was about 150 / 3,000 (about 5\%) over a one-and-a-half year period for www.learningnetworks.org. When we add up the number of posts for both Nuke en Moodle forums, this ratio was about 50 / 100 (about 50\%) over a half year period for LN4LD.

\subsection{Lessons learned}

We identified a number of problems that might underlie the disappointing amount of participants and low level of active participation in the first version of the LN4LD pilot. As noted in the introduction this article focuses on conditions for learner-controlled participation in learning networks and in particular on required policies, usability and structuring of information in advance to stimulate contributions in LN.

Policies. We learned that policies should be stated clearly and not form unwanted obstacles. We first intended to have participants submit a real life problem description (in a PHP-Nuke forum) to get access to the ANs (in Moodle), but this entry policy appeared both too high a threshold and the mechanism was not transparent enough. A description of policies (also containing a description of the mechanism for allowing and making new ANs for self-organisation to occur) was contained in a separate resource that could be read, but only a minority of learners actually did so and no new ANs were added, ratings were given, etc. We feel that policy statements require a central and more visible spot in the LN.

Usability. From the perspective of usability there remains a lot to be improved. Complaints about repeated attempts to register in Nuke indicate that many might have tried, but technically failed to participate. The twolayer architecture (PHP-Nuke / Moodle) without single logon was not transparent to most participants, indicated by the observation that the majority ( $80,8 \%)$ of participants could not find the way through to the Moodle-layer. During the study we changed the text of the home page into a more motivating one, but still believe we need to trigger and motivate visitors to actually come and stay in. Ways to tackle this might be adding more dynamic content (initially very text-oriented), lower level content (initially perhaps more appropriate for a small group of experts on higher levels of understanding), by adding working examples, and by limiting the complexity of the navigation.

Structure. Evaluating the amount of pre-designed structure (the seed ANs) we now feel it was good to have initial content, but that we might have been too many assignments and special forums. There were simply too many parties going on for too few participants (Wiley, 2004).

Exchange and contributions. The amount of active participation is small when related to the total level of participation. This is no doubt caused by the problematic usability and structure, but also has to do with reluctance of the majority of participants to actively contribute. Since the 'seeds' might appear too complex and advanced, participants may have been reticent to ask beginners’ questions.

\subsection{Current perceptions and findings (following WBC2005)}

References to WBC2005 Conference papers. Some WBC2005 papers and presentations seem to be of special interest to studies that explore the critical facilities for participation in learning networks.

Regarding such facilities, Professor Starr Roxanne Hiltz' keynote on 'Asynchronous Learning Networks' stressed the importance of collaborative tasks and the concept of 'swift trust' (i.e., temporary teams formed around a clear purpose and common task with a finite life span) (see also Coppola, Hilz, \& Rotter, 2004) as the main prerequisites for active and long lasting communities. This is in line with what we have noticed within LN4LD: active participation is highest when participants can discuss / collaborate on topics with a shared interest or purpose (e.g., how to get runnable LD examples working). Tanguy Coenen's plea to use social software (see proceedings, pages 255-261) might not just be aimed at increasing creativity but also at increased participation in rich computer mediated communication.

Regarding the effective 'seeding' in learning networks, Nick Flor's presentation on the emergence of more or less stable structures in online social systems (see proceedings, pages 79-86) appears specially promising. We would like to further explore the application of such a 'symbol engine' (i.e., a kind of distributed social system based on schemata) in our learning networks, in order to find out more about enabling (collaborative) learning. In this context of modelling distributed social systems, the UNED Madrid presented a metamodel from the COLDEX project (see proceedings, pages 183-190) that provides the research community with interesting 
technological input to solve various design and architectural questions involved in setting up 'learnable' networks (e.g., as a social workplace).

Finally, various presenters pointed out how 'socially aware' autonomous agents might be used to model and facilitate social interactions, navigation and participation in learning networks. Regarding technological mechanisms to improve personalised learner support and navigation in learning network, we are currently investigating and implementing possibilities to integrate these new techniques into adaptive and self-organising learning networks (Koper \& Sloep, 2003). Although we did not yet implement these techniques in the LN4LD pilot, presentations on autonomous agents and navigation tools during WBC (and AC) 2005 have been followed with our keen interest. For instance, Jon Dron's presentation on 'transactional control' (see proceedings, pages 103-110) provides us with an interesting conceptual framework on more adaptive learning and navigation. In the same vein, a presentation on the relation between 'spatial ability' (i.e., the ability to see spatial patterns and to orientate oneself) and navigation (see proceedings, pages 119125) will need to be considered when designing visualisation tools.

Our first findings on incentive mechanisms. After the study period of three months that we reported on in our WBC paper, we continued monitoring participation during the following period of three months, in a second version of the LN4LD pilot. During this latter period, we carried out experimentation with an incentive mechanism aimed to increase active participation. Participation data have only recently been analysed and reported (an article on this study will be published as Hummel et al., 2005). Without being able to provide you with the details of this experimentation here, what we can do is lift a tip of the veil and give a rough impression and preview of the upcoming results.

Experimentation was inspired by Social Exchange Theory, which informs us that participants will contribute more when there is some kind of intrinsic or extrinsic motive (or reward) involved. To test this assumption, we introduced an incentive mechanism (participants could earn extra access by making contributions). We divided the three-month period in three consecutive periods of one month to monitor our participants, with the incentive mechanism only being introduced and available during the middle period. Results indeed show that encouraging participants with an incentive mechanism increases both active and passive participation on all the measurements. More participants were stimulated to contribute to the network. Participants continued to contribute after the reward was withdrawn. Figure 7 visually proves that both periods (first and last), without the incentive mechanism available, account for about one third of the increase in active participation, while the middle period alone, with the incentive mechanism available, accounts for two thirds of the total increase.

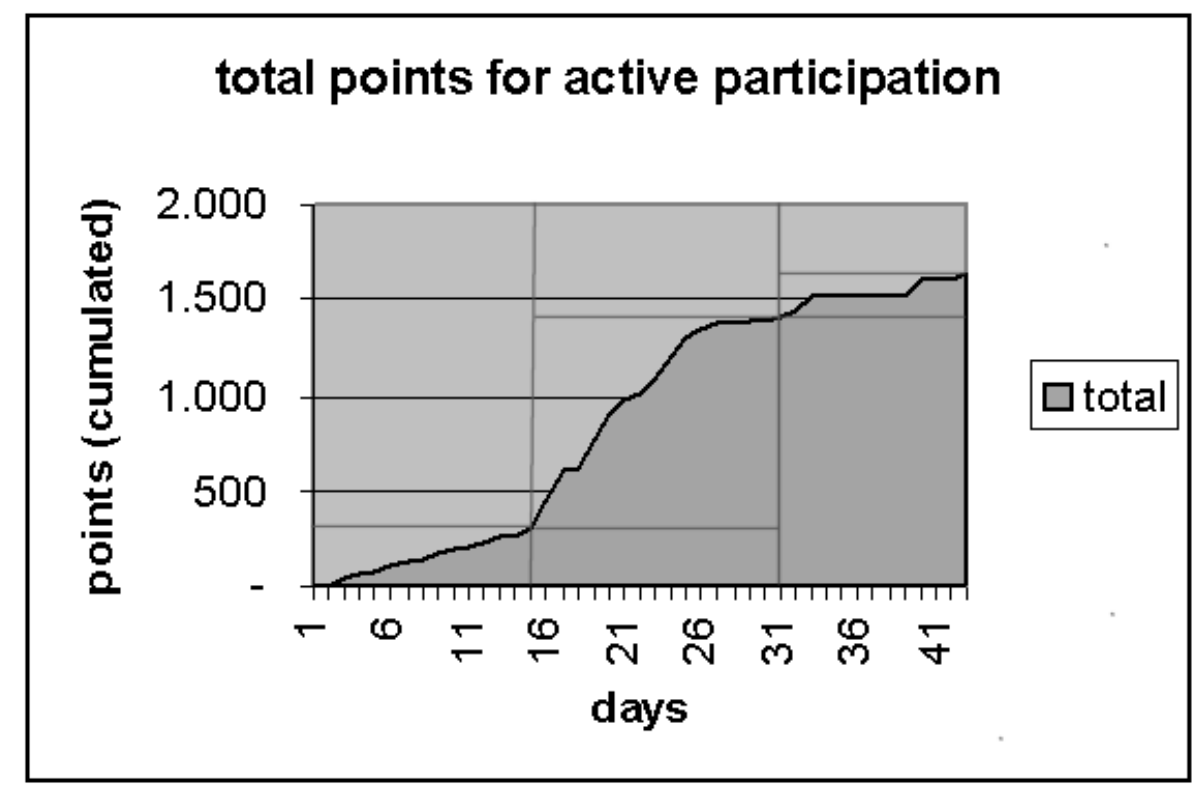

Figure 7 Increase in active participation caused by LN4LD intervention

These results indicate that the choice for extra personal access as an incentive mechanism was in line with the general purpose of the Learning Network (getting more information), as indicated by Social Exchange Theory. Announcing extra access to specific information (running examples not yet available elsewhere) as a reward for participating actively clearly triggered increases during experimentation. 


\section{DISCUSSION}

We presented some preliminary data on participation while setting up the LN4LD and considered from flaws in the implementation of the architectural model. Although parts of the model were be implemented, future implementations will need to be more complete and improved in order to address certain problem (e.g., policies should be as simple and transparent as possible; registration and single logon should be enabled without problems; lower-levelled and more motivating content should be added to attract more users; and initially we should offer a limited amount of structure (e.g. one forum for each AN) and have more structure emerge after when more people have entered the network).

When we apply our general requirements for participation and exchange (Table 3) on these experiences, we can conclude that: requirement 2 (create and use UOLs) was fulfilled; requirements 3 (policies), 12 (reward system) and 16 (usability) need improvement; and that requirements 6 (heterogeneous participation) and 8 (dialogue) have appeared most problematic during this study.

Most successful communities of practice (e.g., Slashdot) have been characterised by a large number of persons (agents), possibilities for feedback (persons leaving clues and cues for others), and a large number of interactions between persons. There obviously will be more interactions when more people are using the same spaces. It now appears for LN4LD that there are too many spaces for too few people and so the opportunities for interaction are small. Here we can only draw a thin line between too much and too little structuring. Wiley (2004) argues that budding communities of practice might be nipped in the bud by providing too many facilities, leaving no room for the community to self-organise their own structure and facilities. He proposes starting with a minimal set, consisting of: 1. one or few forums; 2. identifiable contributions (accounts); 3. kudos (reward) and fire alarms (punishment). This set is available in LN4LD, but forums and content might be too many or too complex to start with. As a first future line of research into ways to facilitate participation, further motivational research will be needed to analyse content with learners needs, and ways to spread access both broadly and deeply. Guzdial (1997) argues that when more participation is needed, it must also be explicitly encouraged through features like synchronous collaboration, which are currently lacking in LN4LD.

In addition to improving usability and structuring, our experiences lead us to the conclusion that we should introduce additional policies for effective exchange, such as a transparent incentive mechanism for active participation. Some kind of 'token economy' would then allow users to earn points for making contributions in order to attain a certain reward. Motivating users with external rewards is known to have drawbacks, but has also been successfully introduced in domains like economics and social psychology (Ryan \& Deci, 2000). Research has shown that when we can motivate persons intrinsically, they want to understand (instead of just memorize) (Bruinsma, 2003), they are more curious and at ease (Levesque, Zuehlke, Stanek, \& Ryan, 2004), they are more inclined to cooperate and exchange knowledge, they show more exploratory behaviour (Wolters \& Pintrich, 1998) , they have a lower chance of dropping out (Hardre \& Reeve, 2003) and they often perform better (Ryan \& Deci, 2000). These learners demonstrate exactly the behaviour we assume necessary for flexible learning networks (Koper \& Sloep, 2003). More formal, program-centred types of education often stand in the way of intrinsic motivation, because of their mandatory character.

Recent findings on using incentive mechanisms to increase the level of active participation in learning networks appear very promising (Hummel et al., 2005). Further articles will report whether the incentive mechanism approach helps to increase active participation when applying other rewards and when combining incentives in combination with face to face meetings (blended learning).

\section{References}

Aspin, D. N., \& Chapman, J. D. (2000). Lifelong learning: concepts and conceptions. International Journal of lifelong education, 19(1), 2-19.

Bruinsma, M. (2003). Leidt hogere motivatie tot betere prestaties? [Does higher motivation result in higher achievement?]. Pedagogische Studiën, 80, 226-238.

Card, S. K., Robertson, G. G., \& York, W. (1996). The WebBook and the Web Forager: An Information Workspace for the World-Wide Web. Paper presented at the Conference on Human Factors in Computing Systems.

Coppola, N.W., Hiltz, S.R., \& Rotter, N. (2001). Building trust in Virtual Teams. IEEE Transactions on Professional Interactions, 47, 2, 95-104.

De Paula, R., Fischer, G., \& Ostwald, J. (2001). Courses as seeds: expectations and realities. Paper presented at the European CSCL 2001, Maastricht, The Netherlands.

De Paula, R. ( 2003). Active Learning Networks : Designing for Computer Supported Social Networks in Special Education Environments. Paper presented at the ECSCW'03 Workshop on Social Networks, 14-18 September, 2003, Helsinki, Finland. Retrieved Oct 16, 2003, from: http://www.ischool.washington.edu/mcdonald/ecscw03/papers/depaulaecscw03-ws.pdf

Dougiamas, M. (2004). Moodle. Retrieved December 12th, 2004, from http://moodle.org/

Field, J. (2001). Lifelong education. International Journal of Lifelong Education, 20(1/2), 3-15. 
Fischer, G., \& Ostwald, J. (2002). Transcending the Information Given: Designing Learning Environments for Informed Participation. Paper presented at the Proceedings of ICCE 2002 International Conference on Computers in Education, Auckland, New Zealand.

Griffin, C. (1999). Lifelong learning and social democracy. International Journal of Lifelong Education, 18(5), 329-342.

Guzdial, M. (1997). Information Ecology of Collaborations in Educational Settings: Influence of Tool. Paper presented at the CSCL '97, Toronto, Ontario, Canada.

Hardre, P., \& Reeve, J. (2003). A motivational model of rural students intentions to persist in, versus drop out of, in high school. Journal of Educational Psychology, 95, 347-356.

Henri, F. (1992). Computer-conferencing and content analysis. In A. R. Kaye (Ed.), Collaborative learning through computer conferencing: The Najaden papers (pp. 117-136). London: Springer-Verlag.

Henri, F. (1994). Distance Learning and Computer-Mediated Communication: Interactive, Quasi-interactive or Monologue? In C. O’Malley (Ed.), Computer Supported Collaborative learning (pp. 145-161). London: Springer-Verlag.

Hummel, H.G.K., Burgos, D., Tattersall, C., Brouns, F., Kurvers, H., \& Koper, E.J.R. (2005). Encouraging Participation in Learning Networks using Incentive Mechanisms. Manuscript submitted to Journal of Computer Assisted Learning.

IMS-LD (2003). IMS Learning Design Specification. Retrieved February 27th, 2004, from http://www.imsglobal.org/learningdesign/index.cfm

Koper, E. J. R., Giesbers, B., Van Rosmalen, P., Sloep, P., Van Bruggen, J., Tattersall, C., et al. (2004). A Design Model for Lifelong Learning Networks. Interactive Learning Environments, (in press).

Koper, E. J. R., \& Sloep, P. B. (2003). Learning Networks: connecting people, organizations, autonomous agents and learning resources to establish the emergence of effective lifelong learning.

Koper, E. J.R., Hermans, H., Vogten, H., \& Brouns, F. (2000). EML 1.0. Retrieved December 12th, 2004, from http://hdl.handle.net/1820/81

Koper, E. J. R., Pannekeet, K., Hendriks, M., \& Hummel, H. G. K. (2004). Building Communities for the Exchange of Learning Objects: Theoretical foundations and requirements. ALT-J Research in Learning Technology, 12(1), 21-35.

Koper, E. J. R., \& Tattersall, C. (2004). New directions for lifelong learning using network technologies. British Journal of Educational Technology, 35(6), 689-700.

Levesque, C., Zuehlke, A. N., Stanek, L. R., \& Ryan, R. M. (2004). Autonomy and competence in German and American university students. Journal of Educational Psychology, 95, 68-85.

Looi, C. K. (2001). Enhancing learning ecology on the Internet. Journal of Computer Assisted Learning, 17(1), 13-20.

Mevarech, Z. R., \& Kramarski, B. (2003). The effects of metacognitive training versus worked-out examples on students' mathematical reasoning. British Journal of Educational Psychology,, 73, 449-471.

Müller, R. M., Spiliopoulou, M., \& Lenz, H.-J. (2001). Paper presented at the International Conference on Advances for Infrastructure in e-business, e-education, e-science, and e-medicine, L'Aquila, Italy.

Nelson, L. M. (1999). Collaborative problem solving. In C. M. Reigeluth (Ed.), Instructional design theories and models: A new paradigm of instructional theory (pp. 241-267). Hillsdale, NJ:: Lawrence Erlbaum Associates.

Olsen, M. (1965). The logic of collective action. Cambridge, MA: Harvard University Press.

PHP-Nuke. (2004). PHP-Nuke 4. Retrieved December 12th, 2004, from http://www.phpnuke.org/

Preece, J. (2000). Online communities: designing usability, supporting sociability. Chichester: Wiley.

Rawlings, A., Van Rosmalen, P., Koper, E. J. R., Rodrigues-Artacho, M., \& Lefrere, P. (2002). Survey of Educational Modelling Languages. Brussels: CEN/ISSS WS/LT Learning Technologies Workshop.

Ryan, R. M., \& Deci, E. L. (2000). Self-determination theory and the facilitation of intrinsic motivation, social development, and well being. American Psychologist, 50, 68-78.

VBulletin. (2004). VBulletin. Retrieved December 12th, 2004, from http://www.vbulletin.com

Wasserman, S., \& Faust, K. (1994). Social Network Analysis: Methods and Applications. Cambridge: Cambridge University Press.

Wiley, D. A., \& Edwards, E. K. (2002). Online self-organizing social systems: The decentralized future of online learning. Quarterly Review of Distance Education.

Wiley, D.A. (2004). Personal communication, Sept 20, 2004.

Wolters, C. A., \& Pintrich, P. A. (1998). Contextual differences in student motivation and self-regulated learning in mathematics, English and social studies classrooms. Instructional Science,, 26, 27-47. 